của $A D C$, một thành phần quan trọng của chuỗi xung khuếch tán.

\section{KẾT LUÂ̂N}

Nghiên cứu của chúng tôi chứng minh rằng DWI giúp xác định u ở NV chính xác hơn CT. Trong số những bệnh nhân có PIRADs IV và PIRADs V, DWI chính xác hơn trong xác định UTTTL ở NV hơn là CT, tuy nhiên không có sự khác biệt đáng kể giữa bệnh nhân có độ thấp hơn. Mặc dù vậy, một số lượng không nhỏ bệnh nhân có DWI âm tính nhưng có độ UTTTL cao. Những phát hiện này nên được cân nhắc trong phân tích CHT tuyến tiền liệt xác định UTTTL.

\section{TÀI LIỆU THAM KHẢO}

1. Turkbey B, Rosenkrantz AB, Haider MA, et al. Prostate Imaging Reporting and Data System Version 2.1: 2019 Update of Prostate Imaging Reporting and Data System Version 2. Eur Urol. 2019;76(3):340-351. doi:10.1016/j.eururo.2019.02.033

2. Lee H, Hwang SI, Lee HJ, Byun S-S, Lee SE, Hong SK. Diagnostic performance of diffusionweighted imaging for prostate cancer: Peripheral zone versus transition zone. PLoS One. 2018;13(6):e0199636.

doi:10.1371/journal.pone.0199636

3. Scheenen TWJ, Rosenkrantz AB, Haider MA, Fütterer JJ. Multiparametric Magnetic Resonance
Imaging in Prostate Cancer Management: Current Status and Future Perspectives. Invest Radiol. 2015;50(9):594-600.

doi:10.1097/RLI.0000000000000163

4. Moosavi B, Flood TA, Al-Dandan o, et al, Multiparametric MRI of the anterior prostate gland: clinical-radiological-histopathological correlation. Clin Radiol. 2016;71(5):405-417. doi:10.1016/ j.crad.2016.01.002

5. Akin O, Sala E, Moskowitz CS, et al. Transition zone prostate cancers: features, detection, localization, and staging at endorectal MR imaging. Radiology. 2006;239(3):784-792. doi:10.1148/ radiol.2392050949

6. Polanec S, Helbich TH, Bickel $H$, et al. Headto-head comparison of PI-RADS v2 and PI-RADS v1. Eur J Radiol. 2016;85(6):1125-1131. doi:10.1016/j.ejrad.2016.03.025

7. Wysock JS, Mendhiratta N, Zattoni F, et al. Predictive value of negative $3 \mathrm{~T}$ multiparametric magnetic resonance imaging of the prostate on 12core biopsy results. BJU Int. 2016;118(4):515-520. doi:10.1111/bju.13427

8. Le JD, Tan N, Shkolyar E, et al. Multifocality and prostate cancer detection by multiparametric magnetic resonance imaging: correlation with whole-mount histopathology. EurUrol. 2015;67(3): 569-576. doi:10.1016/j.eururo.2014.08.079

9. Branger $N$, Maubon $T$, Traumann $M$, et al. Is negative multiparametric magnetic resonance imaging really able to exclude significant prostate cancer? The real-life experience. BJU Int. 2017;119(3):449-455. doi:10.1111/bju.13657

\title{
HIÊUU QUẢ ĐIỀU TRỊ CỦA PHÁC Đồ BORTEZOMIB, CYCLOPHOSPHAMIDE VÀ DEXAMETHASONE (VCD) TRÊN BỆNH NHÂN ĐA U TỦY CÓ SUY GIẢM CHỨC NĂNG THÂ̂N
}

\author{
Lê Bảo Ngọc ${ }^{1,2}$, Suzanne Monivong Cheanh Beaupha ${ }^{1,2}$
}

\section{TÓM TẮT}

Đặt vấn đề: Đa u tủy là một bệnh lý ung thư huyết học thường gặp, gây rối loạn chức năng nhiêu cơ quan. Tổn thương thận là một trong những biến chứng phổ biến nhất của bệnh đa u tủy. Nhiều khuyến cáo trên thế giới hiện nay đã lựa chọn phác đồ VCD (bortezomib, cyclophosphamide và dexamethasone) là phác đồ ưu tiên cho bệnh nhân đa u tủy có suy giảm chức năng thận. Tại Việt Nam còn ít nghiên cứu về vấn đề này. Mục tiêu nghiên cứu: Đánh giá hiệu quả điều trị của phác đồ bortezomib, cyclophosphamide và dexamethasone (VCD) trên bệnh nhân đa u tủy mới chẩn đoán có suy giảm chức nẳng

\footnotetext{
${ }^{1}$ Đại học Y Dược TP. Hồ Chí Minh

${ }^{2}$ Bềnh viện Chợ Rẫy

Chịu trách nhiệm chính: Lê Bảo Ngọc

Email: lebaongoc94@gmail.com

Ngày nhận bài: 4.6.2021

Ngày phản biện khoa học: 28.7.2021

Ngày duyệt băi: 5.8.2021
}

thận. Đối tượng và phương pháp nghiên cứu: Đây là nghiên cứu mô tả hồi cứu được thực hiện tại khoa Huyết học bệnh viện Chợ Rẫy trong khoảng thời gian từ năm 2015-2020 ở bệnh nhân từ 18 tuổi trở lên, mới được chẩn đoán đa u tủy và có tăng creatinin máu > $2 \mathrm{mg} / \mathrm{dL}$ hoặc giảm độ lọc cầu thận eGFR < 60 $\mathrm{mL} /$ phút $/ 1.73 \mathrm{~m}^{2}$, được điều trị bằng phác đồ bortezomib, cyclophosphamide và dexamethasone (VCD). Kết quả: Chúng tôi thu thập được 40 bệnh nhân có độ tuổi là $53,4 \pm 9,5$ tuổi, nam giới chiếm $77,5 \%$, creatinin máu là $4,6 \pm 3,2 \mathrm{mg} / \mathrm{dL}$. Sau hoá trị với 4 chu kỳ bằng phác đồ VCD có $77 \%$ bệnh nhân đạt đáp ứng lui bệnh một phần hoặc hơn ( $\geq \mathrm{PR})$, trong đó đạt lui bệnh một phần rất tốt (VGPR) là $27 \%$. Tỷ lệ đáp ứng thận nói chung đạt $85 \%$, trong đó $57 \%$ đáp ứng hoàn toàn (CRrenal), $10 \%$ đáp ứng một phần (PRrenal) và $18 \%$ đáp ứng tối thiểu (MRrenal). Có sự tương quan thuận có ý nghĩa thống kê giữa đáp ứng thân và đáp ứng lui bệnh sau hoá trị với $p=0,002$. Kểt luận: Phác đồ VCD có hiệu quả điều trị cao trong cả đáp ứng lui bệnh và cải thiện chức năng thận trên bệnh nhân đa u tuỷ mới chẩn đoán có suy giảm chức 
năng thận.

Tư khóa: đa u tuỷ, suy giảm chức năng thận, bortezomib, cyclophosphamide, dexamethasone.

\section{SUMMARY}

TREATMENT EFFICACY OF BORTEZOMIB, CYCLOPHOSPHAMIDE AND DEXAMETHASONE (VCD) REGIMENS IN MULTIPLE MYELOMA

PATIENTS WITH RENAL IMPAIRMENT

Background: Multiple myeloma is a common hematologic malignancy, causing multiple organ dysfunction. Kidney injury is one of the most common complications of multiple myeloma. Current guidelines recommended the VCD regimen (bortezomib, cyclophosphamide and dexamethasone) as the preferred regimen for patients with multiple myeloma and renal impairment. In Vietnam, there are few studies on this context. Objective: To evaluate the treatment efficacy of bortezomib, cyclophosphamide and dexamethasone (VCD) regimens in newly diagnosed multiple myeloma patients with renal impairment. Materials and Methods: A retrospective descriptive study had been conducted at the Department of Hematology, Cho Ray Hospital during the period from 2015 to 2020 . Study population included patients who were aged of 18 years and older, newly diagnosed with multiple myeloma, had serum creatinine level greater than $2 \mathrm{mg} / \mathrm{dL}$ or decreased glomerular filtration rate eGFR $<60$ $\mathrm{mL} / \mathrm{min} / 1.73 \mathrm{~m}^{2}$. These patients were treated with regimen of bortezomib, cyclophosphamide, and dexamethasone (VCD). Results: We collected 40 patients with age $53.4 \pm 9.5$ years old, male accounted for $77.5 \%$, serum creatinine level was 4.6 $\pm 3.2 \mathrm{mg} / \mathrm{dL}$. After chemotherapy with 4 cycles of VCD regimen, $77 \%$ of patients achieved partial remission response or better ( $\geq P R)$, of which very good partial remission (VGPR) was $27 \%$. The overall renal response rate was $85 \%$, of which $57 \%$ had a complete response (CRrenal), 10\% had a partial response (PRrenal) and $18 \%$ had a minimal response (MRrenal). There was a statistically significant positive correlation between renal response and remission response after chemotherapy with $p=0.002$. Conclusion: Our study revealed that the VCD regimen was highly effective in both remission response and renal function improvement in newly diagnosed multiple myeloma patients with renal impairment.

Keywords: multiple myeloma, renal impairment, bortezomib, cyclophosphamide, dexamethasone.

\section{I. ĐĂT VẤN ĐỀ}

Đa u tủy là một bệnh lý ung thư huyết học thường gặp, đặc trưng bởi sự tăng sinh ác tính dòng tương bào tích lũy trong tủy xương sản xuất globulin miễn dịch đơn dòng, biểu hiện đăc trưng trên lâm sàng bởi nhiều ổ hủy xương dẩn đến gãy xương bệnh lý và rối loạn chức năng nhiều cơ quan, bao gồm: suy thận, thiếu máu, tăng canxi máu, các triệu chứng thần kinh... Tổn thương thận là một trong những biến chứng phổ biến nhất của bệnh đa u tủy. Hơn $50 \%$ bệnh nhân tiến triển đển suy thận trong suốt thời gian bệnh, với $20-50 \%$ bệnh nhân biểu hiện suy thân tai thời điểm chẩn đoán và hơn $12 \%$ bênh nhân cần điều trị thay thế thân [4]. Sự xuất hiên của bệnh thận trong đa u tủy là một chỉ số tiển lượng kém. Thời gian sống trung bình của bệnh nhân suy thận từ trung bình đến nặng là $9-13$ tháng, trong khi đó là 34 - 36 tháng ở những người có chức năng thận bình thường [7]. Đáp ứng nhanh và sâu với hóa trị là rất quan trọng để phưc hồi chức năng thân. Hiện nay, nhiều khuyên cáo trên thế giới đã lựa chọn phác đồ VCD (bortezomib, cyclophosphamide và dexamethasone) là phác đồ ưu tiên cho bệnh nhân đa u tủy có suy giảm chức năng thận ở cả bênh nhân có và không có chỉ định ghép tế bào gốc. Những năm gần đây, tại Việt Nam nói chung và bệnh viện Chợ Rẫy nói riêng đã áp dụng rộng rãi phác đồ VCD trong điều trị bệnh đa u tủy. Tuy nhiên, chưa có nghiên cứu nào đánh giá đáp ứng điều trị cũng như tỷ lệ cải thiện chức năng thận trên nhóm bệnh nhân đa u tủy mới chẩn đoán được điều trị với phác đồ này. Vì vậy, chúng tôi tiến hành nghiên cứu này để đánh giá hiệu quả điều trị của phác đồ bortezomib, cyclophosphamide và dexamethasone (VCD) trên bệnh nhân đa u tủy mới chẩn đoán có suy giảm chức năng thận.

\section{II. ĐỐI TƯỢNG VÀ PHƯƠNG PHÁP NGHIÊN CỨU}

Đối tượng nghiên cứu: Đây là nghiên cứu mô tả hồi cứu được thực hiện tại khoa Huyết học bênh viện Chợ Rẫy trong khoảng thời gian từ nămm 2015-2020. Nghiên cứu được tiến hành với sự chấp thuận của Hội đồng Đạo Đức trong nghiên cứu Y Sinh Học tại Đại học Y Dược Thành phố Hồ Chí Minh và bệnh viện Chợ Rẫy.

Tiêu chuân nhận vào: Những bệnh nhân từ đủ 18 tuổi trở lên, mới được chẩn đoán xác định đa u tủy theo tiêu chuẩn của Hiệp hội nghiên cứu Đa u tủy quốc tế (IMWG) 2014 [5], có tăng creatinin máu $>2 \mathrm{mg} / \mathrm{dL}$ hoặc giảm độ lọc cầu thận eGFR < $60 \mathrm{~mL} /$ phút $/ 1.73 \mathrm{~m}^{2}$, được điều trị bằng phác đồ bortezomib, cyclophosphamide và dexamethasone (VCD), hồ sơ bệnh án đầy đủ thông tin nghiên cứu theo mẫu thu thập số liệu.

Tiêu chuẩn loại trừ: Chúng tôi loại khỏi nghiên cứu những hồ sơ bệnh án không đầy đủ thông tin nghiên cứu theo mẫu thu thập số liệu.

Biến số nghiên cứu: Trong nghiển cứu này, đáp ứng điều trị sau 4 chu kỳ được đánh giá theo tiêu chuẩn của Hiệp hội nghiên cứu Đa u tủy quốc tế (IMWG) 2014 [5] thành 5 mức: đáp 
ứng một phần rất tốt (VGPR), đáp ứng một phần (PR), đáp ứng tối thiểu (MR), bệnh ổn định (SD) và bệnh tiến triển $(P D)$. Đồng thời, đánh giá đáp ứng thận sau điều trị được phân nhóm dựa theo tiêu chuẩn của Hiệp hội nghiên cứu Đa u tủy quốc tế (IMWG) 2016 [2] gồm: đáp ứng hoàn toàn (CRrenal), đáp ứng một phần (PRrenal), đáp ứng tối tiểu (MRrenal) và không đáp ứng (NRrenal). Ngoài ra chúng tôi cũng thu thập các số liệu về dịch tễ, lâm sàng, cận lâm sàng trong quá trình điều trị của bệnh nhân từ hồ sơ bệnh án.

Xử lý thống kê: Nhập và xử lý số liệu bằng phần mềm Stata 14.1 for Mac. Các biến định tính được trình bày dưới dạng tần số và tỷ lệ \%. Các biến liên tục phân phối chuẩn được mô tả bằng trung bình \pm độ lệch chuẩn, nếu phân phối không chuẩn được mồ tả bằng trung vị (tứ phân vị $25^{\text {th }}$ $75^{\text {th }}$ ). Chia dân số bệnh nhân thành 2 nhóm: độ lọc cầu thận eGFR $<30 \mathrm{~mL} /$ phút/ $1.73 \mathrm{~m}^{2}$ và $\geq 30$ $\mathrm{mL} /$ phút $/ 1.73 \mathrm{~m}^{2}$. Để phân tích đáp ứng điều trị, chúng tôi phân thành 2 nhóm: đáp ứng một phần hoặc hơn ( $\geq P R)$ và thấp hơn đáp ứng một phần (<PR), đồng thời cũng phân thành 2 nhóm đáp ứng thận gồm: đáp ứng một phần hoặc hơn ( $\geq$ PRrenal) và thấp hơn đáp ứng một phần (< PRrenal). Để so sánh tỷ lệ giữa 2 nhóm sử dụng phép kiểm chi bình phương. Các phép kiểm có ý nghĩa thống kê khi giá trị $\mathrm{p}<0,05$.

\section{KẾT QUẢ NGHIÊN CỨU}

Trong thời gian tiến hành nghiên cứu, chúng tôi thu thập được 40 bệnh nhân thoả tiêu chuẩn nhận vào nghiên cứu, trong đó có 31 nam (77.5\%) và 9 nữ (22.5\%). Độ tuổi trung bình là 53 tuổi, độ tuổi lớn nhất là 70 tuổi, độ tuổi nhỏ nhất là 32 tuổi.

Đặc điểm lâm sàng và cận lâm sàng của bệnh nhân trong nghiên cứu của chúng tôi được mổ tả trong Bảng 1. Các đặc điểm nhân trắc học như tuổi, BMI và đặc điểm triệu chứng lâm sàng không có sự khác biệt giữa 2 nhóm phân theo chức năng thận. Tuy nhiên, nam giới chiếm tỷ lệ cao hơn ở nhóm bệnh nhân có chức năng thận lúc chẩn đoán giảm nặng (eGFR $<30 \mathrm{~mL} /$ phút/ $1.73 \mathrm{~m}^{2}$ ) có ý nghĩa thống kê, với chỉ số $\mathrm{p}=0,03$.

Các chỉ số công thức máu (Hb, WBC, PLT) và tỷ lệ tương bào trong tuỷ tương tự nhau giữa các phân nhóm thận. Có sự khác biệt rõ rệt về chỉ số $\beta 2$ microglobulin trong máu ở 2 phân nhóm thận, chỉ số này cao hơn đáng kể ở nhóm bệnh nhân suy giảm chức năng thận nặng (eGFR < $30 \mathrm{~mL} / \mathrm{phút} / 1.73 \mathrm{~m}^{2}$ ) có ý nghĩa với $p=0,01$.

Bảng 1. Đặc điểm lâm sàng, cận lâm sàng dựa theo phân nhóm chức năng thận

\begin{tabular}{|c|c|c|c|c|}
\hline & $\begin{array}{c}\text { Tổng } \\
(n=40)\end{array}$ & $\begin{array}{c}\text { eGFR }<30 \\
\mathrm{~mL} / \mathrm{phút} / 1.73 \mathrm{~m}^{2} \\
(\mathrm{n}=29)\end{array}$ & $\begin{array}{c}\text { eGFR } \geq 30 \\
\mathrm{~mL} / \mathrm{phút} / 1.73 \mathrm{~m}^{2} \\
(\mathrm{n}=11)\end{array}$ & p value \\
\hline \multicolumn{5}{|c|}{ Đặc điếm chung } \\
\hline Tuối (năm) & $53,4 \pm 9,5$ & $52,3 \pm 9,1$ & $56,5 \pm 10,4$ & 0,22 \\
\hline Giới nam & $31(77,5)$ & $25(86,2)$ & $6(54,5)$ & 0,03 \\
\hline BMI $\left(\mathrm{kg} / \mathrm{m}^{2}\right)$ & $20,6 \pm 2,0$ & $20,4 \pm 1,8$ & $21,1 \pm 2,3$ & 0,33 \\
\hline \multicolumn{5}{|c|}{ Lâm sàng } \\
\hline Thiếu máu & $39(97,5)$ & $29(100)$ & $10(90,9)$ & - \\
\hline Đau xương & $35(87,5)$ & $25(86,2)$ & $10(90,9)$ & 0,58 \\
\hline Triệu chứng $\mathrm{B}$ & $24(60)$ & $19(65,5)$ & $5(45,5)$ & 0,25 \\
\hline \multicolumn{5}{|c|}{ Cận lâm sàng } \\
\hline $\mathrm{Hb}(\mathrm{g} / \mathrm{L})$ & $77,8 \pm 17,6$ & $75 \pm 17,2$ & $85 \pm 17,5$ & 0,11 \\
\hline WBC (G/L) & $8,8 \pm 3,4$ & $8,8 \pm 3,0$ & $8,6 \pm 4,3$ & 0,88 \\
\hline PLT (G/L) & $229 \pm 138$ & $223 \pm 129$ & $244 \pm 166$ & 0,68 \\
\hline $\mathrm{BUN}(\mathrm{mg} / \mathrm{dL})$ & $46,7 \pm 26,3$ & $55,5 \pm 25,9$ & $23,6 \pm 4,3$ & 0,0003 \\
\hline Creatinin $(\mathrm{mg} / \mathrm{dL})$ & $4,6 \pm 3,2$ & $5,8 \pm 3,0$ & $1,5 \pm 0,3$ & $<0,001$ \\
\hline eGFR (mL/phút/1.73m²) & $21,5 \pm 15,7$ & $12,5 \pm 5,4$ & $45,1 \pm 6,1$ & $<0,001$ \\
\hline $\mathrm{Ca}$ TP $(\mathrm{mmol} / \mathrm{L})$ & $2,6 \pm 0,6$ & $2,7 \pm 0,6$ & $2,4 \pm 0,3$ & 0,06 \\
\hline $\mathrm{LDH}(\mathrm{U} / \mathrm{L})$ & $302 \pm 211$ & $273 \pm 134$ & $376 \pm 338$ & 0,17 \\
\hline$\beta 2$ microglobulin $(\mu \mathrm{g} / \mathrm{L})$ & $19068 \pm 18007$ & $23341 \pm 19459$ & $7801 \pm 3424$ & 0,01 \\
\hline Tỷ lệ tương bào tuỷ (\%) & $37,3 \pm 25,7$ & $34,6 \pm 25,8$ & $44,4 \pm 25,4$ & 0,29 \\
\hline \multicolumn{5}{|c|}{ Loại Immunoglobulin } \\
\hline IgG & $20(50)$ & $14(48,3)$ & $6(54,5)$ & \multirow{3}{*}{ - } \\
\hline IgA & $5(12,5)$ & $3(10,3)$ & $2(18,2)$ & \\
\hline IgM & $0(0)$ & $0(0)$ & $0(0)$ & \\
\hline
\end{tabular}




\begin{tabular}{|c|c|c|c|c|}
\hline \multicolumn{5}{|c|}{ Loai chuối nhe } \\
\hline Kappa & $27(67,5)$ & $21(72,4)$ & $6(54,5)$ & \multirow{2}{*}{0,37} \\
\hline Lambda & $11(27,5)$ & $7(24,1)$ & $4(36,4)$ & \\
\hline \multicolumn{5}{|c|}{ Giai đoan ISS } \\
\hline I & $1(2,5)$ & $0(0)$ & $1(9,1)$ & \multirow{3}{*}{ - } \\
\hline II & $2(5)$ & $0(0)$ & $2(18,2)$ & \\
\hline III & $37(92,5)$ & $29(100)$ & $8(72,7)$ & \\
\hline
\end{tabular}

Giá trị là trung bình \pm độ lệch chuẩn hoặc số lượng (\%).

Theo kết quả chúng tôi ghi nhận được, sau khi hoá trị 4 chu kỳ với phác đồ VCD có $77 \%$ bệnh nhân đạt đáp ứng lui bênh một phẩn hoặc hơn $(\geq \mathrm{PR})$, trong đó đạt lui bệnh một phần rất tốt (VGPR) là $27 \%$ (Hình 1A). Tỷ lệ đáp ứng thận nói chung đạt $85 \%$, trong đó $57 \%$ đáp ứng hoàn toàn (CRrenal), $10 \%$ đáp ứng một phần (PRrenal) và $18 \%$ đáp ứng tối thiểu (MRrenal) (Hình 1B).
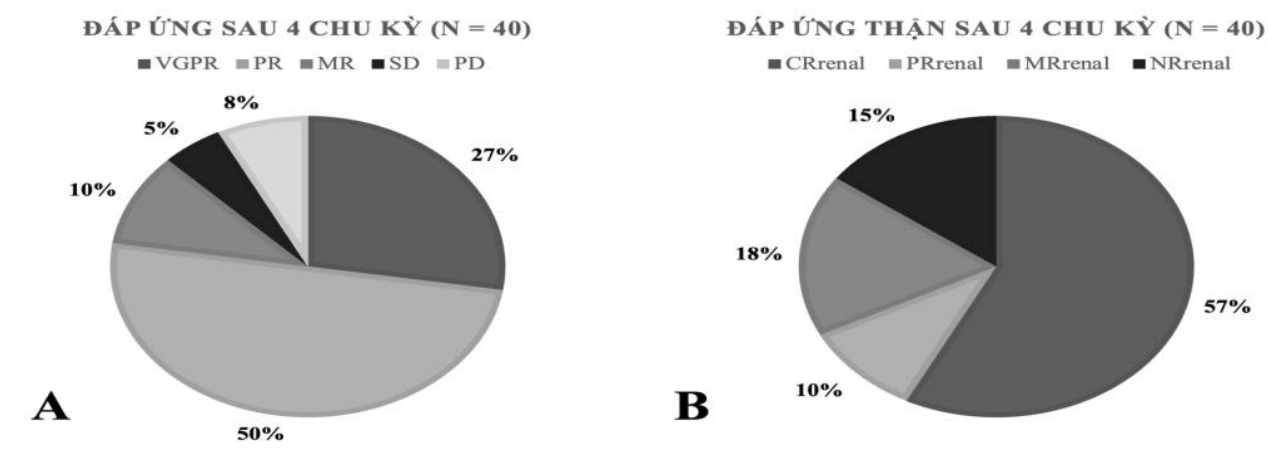

\section{Hình 1. 1A-Đánh giá đáp ứng điều trị sau 4 chu kỳ VCD, 1B-Đánh giá đáp ứng thân sau 4 chu kỳ VCD}

Khi phân tích đáp ứng thận theo 2 nhóm đáp ứng lui bệnh gồm đáp ứng một phần hoặc hơn ( $\geq$ $\mathrm{PR}$ ) và thấp hơn đáp ứng một phần $(<\mathrm{PR})$, chúng tồi nhận thấy khi bệnh nhân đáp ứng với điều trị thì chức năng thận cũng cải thiện theo, sự cải thiện này là có ý nghĩa thống kê với $p=0,002$ qua phép kiểm chính xác Fisher (Hình 2). Trong nhóm đáp ứng lui bệnh $\geq P R$ với 31 bệnh nhân, có $80,7 \%$ bệnh nhân đáp ứng thận $\geq$ PRrenal. Ngược lại đối với nhóm đáp ứng lui bệnh < $P R$, tỷ lệ cải thiện chức năng thận $\geq$ PRrenal chỉ đạt 22,2\%.

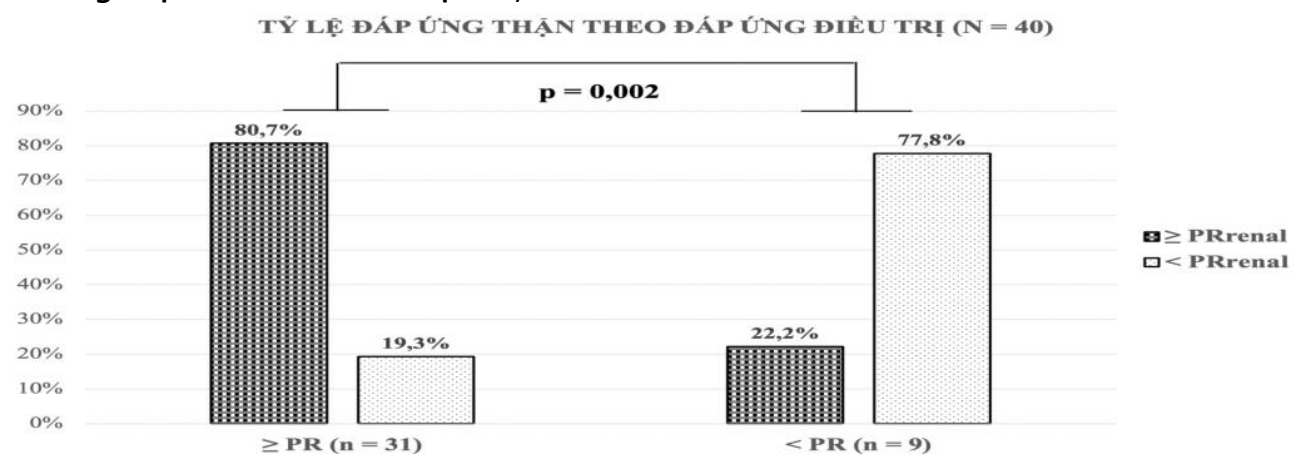

Hình 2. Tỷ lệ đáp ứng thận theo đáp ứng điều trị sau 4 chu kỷ VCD

\section{BÀN LUÂN}

Nghiên cứu của chúng tôi đánh giá hiệu quả điều trị của phác đồ VCD trên 40 bệnh nhân đa u tuỷ mới chẩn đoán có suy giảm chức năng thận (creatinin máu $>2 \mathrm{mg} / \mathrm{dL}$ hoặc giảm độ lọc cầu thận eGFR < $60 \mathrm{~mL} / \mathrm{phút} / 1.73 \mathrm{~m} 2$ ), đây là nhóm đối tượng có tiên lượng xâu, tăng nguy cơ tử vong sớm ở bệnh nhân đa u tuỷ. Theo y văn, cũng đã có một số tác giả tiến hành đánh giá hiệu quả điều trị của phác đồ có bortezomib trên nhóm đối tượng này.

Khi so sánh về độ tuổi của dân số, nhận thấy độ tuổi trung bình trong nghiên cứu của chúng tôi là 53,4 tuổi, thấp hơn so với nghiên cứu EVOLUTION là 62 tuổi [3], nghiên cứu của Costa và cộng sự là 63 tuổi[1]. Tỷ lệ đáp ứng lui bệnh sau hoá trị phác đồ VCD trong nghiên cứu của chúng tôi gần tương đồng với các tác giả khác 
với 77\% bệnh nhân trong nghiên cứu của chúng tôi đạt đáp ứng một phần hoặc hơn, trong nghiên cứu EVOLUTION tỷ lệ này là $75 \%$ [3], trong thử nghiệm của Reeder và cộng sự là $88 \%$ [6] và trong nghiên cứu của Costa và cộng sự là 100\%[1]. Chúng tôi ghi nhận được mức creatinin trung bình của bệnh nhân là $4,6 \mathrm{mg} / \mathrm{dL}$ cao hơn so trong nghiên cứu của Costa và cộng sự có mức creatinin trung bình trong nhóm bệnh nhân suy giảm chức năng thận là $3,5 \mathrm{mg} / \mathrm{dL}$ [1]. Tuy nhiên tỷ lệ cải thiện chức năng thận trong nghiên cứu của chúng tôi đạt được khá cao và gần tương đồng với tác giả này. Cụ thể, nghiên cứu của chúng tôi có $85 \%$ bệnh nhân đạt đáp ứng thâan nói chung, trong đó $57 \%$ đáp ứng hoàn toàn (CRrenal), $10 \%$ đáp ứng một phần (PRrenal) và $18 \%$ đáp ứng tối thiểu (MRrenal), còn trong nghiên cứu của Costa và cộng sự, các tỷ lệ này lần lượt là $71,4 \%, 35,7 \%$ (CRrenal), $28,5 \%$ (PRrenal) và $7,1 \%$ (MRrenal) [1]. Nghiên cứu của chúng tôi cũng phân tích được rằng có sự tương quan thuận có ý nghĩa thống kê giữa đáp ứng thận và đáp ứng lui bệnh sau hoá trị với $\mathrm{p}=0,002$.

Tổn thương thận là một trong những biến chứng phổ biến nhất của bệnh đa u tủy. Triệu chứng thường gặp là suy thận và đạm niệu. Tổn thương thận ở bệnh nhân đa u tủy chủ yểu là do tác dụng độc hại của chuỗi nhẹ đơn dòng trên màng đáy của cầu thận và/hoặc ống thận. Tổn thương thận trong đa u tủy có nhiêu dạng khác nhau, nhưng phổ biến nhất là bệnh thận trụ (cast nephropathy), thường dẫn đến tổn thương thận cấp. Tăng calci máu, mất nước, tăng độ nhớt máu, giảm tuần hoàn thận, tăng acid uric máu, thuốc gây độc cho thận (kháng sinh aminoglycoside và/hoặc thuốc chống viêm không steroid) và chất cản quang góp phần vào sự phát triển hoặc làm tăng thêm tổn thương thận hiện có bằng cách làm trầm trọng thêm tác dụng độc hại của chuỗi nhẹ [4]. Việc sử dụng các thuốc điều trị mới dẫn đến sự gia tăng đáng kể thời gian sống sót của bệnh nhân đa u tủy với suy giảm chức năng thận, mặc dù suy thận nặng có liên quan đến tăng nguy cơ tử vong sớm. Đã có nhiêuu nghiên cứu chứng minh vai trò của chất ức chế proteasome - bortezomib ở bệnh nhân đa u tủy có suy giảm chức năng thận. Ngoài hoạt động chống đa u tủy, bortezomib giúp ổn định NF-kappaB và điều chỉnh các yếu tố chống chết tế bào theo chương trình (apoptosis) trong các tế bào ống thận [8]. Bortezomib không lọc qua thận, cho phép điêu trị nhanh chóng mà không cần điều chỉnh liều. Việc bổ sung thuốc thứ ba gồm chất điều hòa miễn dịch hoặc tác nhân alkyl hóa hoặc anthracycline thêm vào hai thuốc nền tảng bortezomib và corticosteroid trong điều trị đa u tủy giúp cải thiện tỷ lệ, độ sâu và tốc độ đáp ứng điêu trị của bệnh đa u tủy.

Trong nghiên cứu của chúng tôi, còn một số hạn chế là nghiên cứu hồi cứu dựa trên hồ sơ bệnh án do đó một số biến số có thể không được thu thập đầy đủ, nghiên cứu cỡ mẫu nhỏ, đởn trung tâm. Do vậy cần tiến hành nghiên cứu với cỡ mẫu lớn hơn, đa trung tâm, so sánh hiệu quả của các phác đồ khác nhau.

\section{KẾT LUÂ̂N}

Phác đồ bortezomib, cyclophosphamide và dexamethasone (VCD) có hiệu quả điều trị cao trong cả đáp ứng lui bệnh và cải thiện chức năng thận trên bệnh nhân đa u tuỷ mới chẩn đoán có suy giảm chức năng thận. Có sự tương quan thuận có ý nghĩa thống kề giữa đáp ứng thận và đáp ứng lui bệnh sau hoá trị.

\section{TÀI LIÊU THAM KHẢO}

1. Costa L.J. et al., "Outcomes of patients with multiple myeloma and renal impairment treated with bortezomib, cyclophosphamide, and dexamethasone without plasma exchange", Eur J Haematol, 2012, 89 (5), pp. 432-434.

2. Dimopoulos M.A. et al., "International Myeloma Working Group Recommendations for the Diagnosis and Management of Myeloma-Related Renal Impairment", Journal of Clinical Oncology, 2016, 34 (13), pp. 1544-1557.

3. Kumar S. et al., "Randomized, multicenter, phase 2 study (EVOLUTION) of combinations of bortezomib, dexamethasone, cyclophosphamide, and lenalidomide in previously untreated multiple myeloma", Blood, 2012, 119 (19), pp. 4375-4382.

4. Lum E.L. et al., "Kidney Transplantation in Patients With Active Multiple Myeloma: Case Reports", Transplantation direct, 2017, 3 (8), pp. e200-e200.

5. Rajkumar S.V. et al., "International Myeloma Working Group updated criteria for the diagnosis of multiple myeloma", Lancet Oncol, 2014, 15 (12), pp. e538-548.

6. Reeder C.B. et al., "Cyclophosphamide, bortezomib and dexamethasone induction for newly diagnosed multiple myeloma: high response rates in a phase II clinical trial", Leukemia, 2009, 23 (7), pp. 1337-1341.

7. Reule S. et al., "ESRD due to Multiple Myeloma in the United States, 2001-2010", Journal of the American Society of Nephrology: JASN, 2016, 27 (5), pp. 1487-1494.

8. Sarközi R. et al., "Bortezomib-Induced Survival Signals and Genes in Human Proximal Tubular Cells", Journal of Pharmacology and Experimental Therapeutics, 2008, 327 (3), pp. 645 